\title{
JURISPRUDENCIA GENERAL: DERECHO PENAL \\ (SEGUNDO SEMESTRE 2016)
}

\author{
ELENA GÓRRIZ ROYO \\ Profesora titular de Derecho Penal \\ Universitat de València. Estudi General \\ MARIA MARQUÈS I BANQUÉ \\ Profesora colaboradora de Derecho Penal \\ Universitat Rovira $i$ Virgili \\ NÚRIA TORRES ROSELL \\ Profesora agregada temporal de Derecho Penal \\ Universitat Rovira i Virgili
}

Sumario: 1. Delitos relativos a la ordenación del territorio y el urbanismo. 2. Delitos contra los recursos naturales y el medio ambiente. 3. Delitos relativos a la protección de la flora, la fauna y los animales domésticos.

\section{Delitos relativos a la ordenación del territorio y el urbanismo}

Las sentencias más relevantes en materia de delitos contra la ordenación del territorio, hasta octubre de 2016, han sido dos resoluciones del Tribunal Supremo que han versado, respectivamente, sobre los delitos del artículo $319 \mathrm{CP}$, de otro lado, sobre las prevaricaciones urbanísticas del artículo $320 \mathrm{CP}$.

Centrando, en primer lugar, el análisis sobre la STS núm. 708/2016, de 19 de septiembre, en ella se casa una sentencia de la Audiencia Provincial de Madrid, Sección 1 a en la que se dictó condena por delito urbanístico del artículo 319.1 CP en relación con la circunstancia agravante del artículo 338 CP. La resolución del Tribunal Supremo 
modificó la condena, aplicando el delito del apartado $2^{\circ}$ del artículo $319 \mathrm{CP}$ (en lugar del apartado $1^{\circ}$ ) y excluyó la aplicación de la circunstancia agravante específica.

Los hechos enjuiciados se refieren a las obras realizadas por el acusado durante el año 2011 y los meses anteriores a abril de 2012, en unas parcelas de su propiedad, situadas en Colmenar del (...) (Madrid), para el levantamiento de un cortocircuito motocross. A tal efecto llevó a cabo movimientos de tierras de miles de metros cúbicos, realización de desmontes y terraplenes, con alteración del perfil de la ladera en la parte baja de la parcela, colocación de dos rampas móviles de estructura metálica no ancladas al suelo, aporte de tierras y explanación de las mismas en al menos 6000 metros cuadrados. Aunque realizó todas estas obras, el acusado no solicitó licencia ni autorización, estando la zona afectada incluida en la Orden 903/2001 de 5 de abril de la Consejería del Medio Ambiente de la Comunidad de Madrid por la que se inicia el procedimiento de tramitación del Plan de Ordenación de los Recursos Naturales de la zona de especial protección de las aves silvestres denominada Encinares de los ríos Cofio y Alberche.

Por estos hechos, el acusado fue condenado a la pena de cuatro años y un día de prisión, inhabilitación especial para el derecho de sufragio pasivo, multa de veinticuatro meses y un día, inhabilitación especial para el ejercicio de la profesión u oficio como promotor, constructor o técnico director de edificaciones de cuatro años y un día y a la restauración del suelo al estado anterior a las obras realizadas; todo ello previo informe de la Dirección General del Medio Ambiente sobre la incidencia que en dicha zona pudieran suponer las obras de restauración en el medio ambiente. Asimismo, el tribunal de instancia dictó un Auto de aclaración de la mencionada sentencia en el que se especifica que la condena se refería al tipo agravado del artículo 319.1 CP en relación con el artículo 338 CP.

El primer motivo que alega el recurrente en casación es "error facti" (artículo 849.2 LECRIM) mostrando un total desacuerdo con la valoración jurídica que la sentencia de instancia hizo del dictamen pericial. Así pues, en el FJ $1^{\circ}$ se enjuicia la discrepancia del recurrente sobre la calificación del suelo no urbanizable de especial protección reputando los posibles daños derivados del movimiento de tierras efectuado por el recurrente, como algo opinable o hipotético, sin base real alguna. Entiende que la Sala de instancia llegó a una sentencia condenatoria con base en el dictamen del perito. No obstante, el TS concluye rechazando este motivo, al destacar que el tribunal de instancia tiene libertad de valorar el alcance y precisión del dictamen, en el ejercicio de su función exclusiva, sin perjuicio de que la parte a la que no favorezca pueda acreditar que la valoración del 
tribunal fue arbitraria o absurda. En el caso de autos, se entiende que al describir el dictamen "los posibles efectos negativos del movimiento de tierras realizado por el acusado, en relación a la ordenación del territorio, no condiciona el juicio de subsunción o calificación de la conducta como delictiva. Se trata de una prueba más con los efectos limitados en orden a la calificación jurídica de los hechos". Y sobre este razonamiento se desestima la pretensión del recurrente.

Otro de los argumentos empleados por el recurrente en el FJ $2^{\circ}$ es la vulneración de la presunción de inocencia, y para ello trata de deslegitimar la existencia de antijuridicidad $\mathrm{y}$, alternativamente, de acreditar un error de prohibición a su favor. A tal efecto, el recurrente argumentó que la "obra realizada no resulta conforme a la prueba practicada", ya que la construcción, por cierto, inacabada, fue mínima, consistente en la creación de un "minicircuito", no "cortocircuito" como afirman los hechos probados, dentro de la parcela de su propiedad, para uso exclusivo de su hijo. Además añadía que el informe emitido por los servicios forestales era exagerado, pues la zona tenía la consideración de protegida por el interés “ganadero". Igualmente, la existencia de chalets próximos le hizo pensar que no existiría la prohibición de realizar tales movimientos de tierras con lo que intentó aducir un error de prohibición. No obstante, todos estos motivos son rechazados por el TS razonando que hubo prueba bastante para justificar el relato de hechos probados y la autoría del recurrente (confesión del propio acusado, testimonio de agentes forestales, fotografías e informe pericial). Más aún, el TS entendió destacable la ofensa al bien jurídico a raíz del informe del perito en donde se acreditó el riesgo o peligro típico, al certificar que las obras "pudieron implicar la disminución de territorios de caza para varias especies de fauna, la desaparición de puntos de refugio para la especie -presa de especies emblemáticas-, la desaparición de posibles puntos de nidificación y cría, el incremento de molestias derivadas de nuevos usos y la fragmentación del hábitat. Y que las actividades previstas suponían una variación sustancial de las condiciones acústicas del entorno que podían producir efectos negativos en los animales”.

Pese a ello, el recurrente en el FJ $4^{\circ}$, se opone a la existencia de dolo eventual declarado en la sentencia de instancia e intenta probar ausencia de conciencia de ilegalidad del acto, puesto que — según alegaba - su profesión era la de periodista. El TS rechaza este argumento, contestando que "hay dos datos significativos para llegar a la conclusión de no considerar apreciable la existencia de un error en el acusado. En primer lugar, respecto a sus condiciones personales, el acusado era de profesión periodista y, por lo tanto, con 
un nivel de formación y aptitud suficiente para conocer o buscar información; y, en segundo lugar, respecto de su forma de actuar, el acusado no solicitó autorización ni licencia para la realización de las obras que, como se ha puesto de manifiesto, tuvieron una cierta entidad".

También rechaza el Tribunal Supremo la aplicación de la circunstancia atenuante de reparación del daño (artículo $21.5 \mathrm{CP}$ ) que el recurrente trató de hacer valer en el FJ 5º, alegando que procedió "a disminuir los efectos del daño, porque de inmediato y tan pronto se denunciaron las obras cesó en la continuación de las mismas, sin culminar el proyecto, amén que el delito cometido no le reportó ventaja alguna”. Frente a ello, con razón el TS recuerda que en el apartado $3^{\circ}$ del artículo 319 CP se prevé la medida de reposición del suelo a su estado original y que la conducta del acusado de paralizar las obras es reflejo de que se apreciara aquella medida, de modo que dicha circunstancia se deberá considerar en la extensión de la pena que se imponga, pero no como factor atenuante.

Por otra parte, el motivo que resulta más interesante analizar y por el que esta sentencia establece un criterio relevante en materia de delitos contra la ordenación del territorio se encuentra en el FJ $3^{\circ}$, donde se enjuicia el problema de la irretroactividad penal de una norma extrapenal de complemento. Se parte de constatar que el tipo penal del artículo 319.1 C.P. es un precepto en blanco, que precisa su integración a través de la norma pertinente del orden administrativo. El recurrente alega que la norma administrativa que integró aquel precepto penal, la Orden 903/2001 de la Consejería de Medio Ambiente de la Comunidad de Madrid, era inaplicable, a la vista de la anulación del Decreto dictado por el Consejo de Gobierno de la Comunidad Autónoma 36/2010 de 1 de julio. Reprocha que la acusación del Fiscal se haya construido sobre el Decreto 36/2010, a pesar de haber sido anulado por la STS de 16 de octubre de 2014, en materia de regulación de los espacios protegidos. Dicho Decreto declaraba la zona de las obras de Especial Conservación (ZEC) y el lugar de importancia comunitaria (LIC), denominado "Cuencas de los ríos Alberche y Cofio", aprobando el Plan de Gestión de Espacio Protegido Red Natura 2000. Según el recurrente, la anulación del Decreto trajo consigo la reactivación de la Orden que derogó 903/2001, pero dando una interpretación y alcance como si se tratara del Decreto derogado. En otras palabras, la anulación del decreto habría hecho que el artículo 319.1 CP se tuviera que integrar por una norma más favorable que, en sede penal, debía haber comportado la inaplicación del delito. En consecuencia, "al realizarse la obra en terrenos propios de la zona de protección ganadera, nada tenía que ver con la 
conservación y protección de aves silvestres, conceptos totalmente distintos”. El TS da la razón en este punto al recurrente, sobre la base de que "la declaración de 'especial protección' en nuestro país y en la Comunidad Autónoma de Madrid en tanto se trata de una competencia transferida, le corresponde a dicha Comunidad, que es la que tiene la potestad de llevar a cabo tal declaración, como lo demuestra el Decreto del Consejo de Gobierno de la comunidad madrileña, oportunamente declarado nulo por la Sala Tercera del Tribunal Supremo". Y puesto que uno de los vicios o deficiencias del Decreto era la inconcreta o no bien delimitada zonificación del lugar, "ello podría determinar que todo o parte de la finca en que se realizaron las obras de desmonte y explanación no estuviera incluida dentro de los límites de la zona protegida". En consecuencia, se entendió que hasta que la comunidad autónoma no reconociera la zona como "especialmente protegida" por reconocimiento, asimismo, de un valor ecológico y declarándolo a través de un Decreto, la conducta no podía merecer el mismo reproche penal conforme al artículo 319 apartado $1^{\circ}$ (donde se castiga la construcción, entre otros, en suelos que por su carácter ecológico hayan sido considerados de especial protección). En definitiva, se entiende que la zona era conforme a la legalidad pues era un terreno de especial protección para el ganado, pero nada tenía que ver con las "aves silvestres" de modo que "la Orden 903/2001 inicia el procedimiento, pero no se ha culminado por un Decreto válido que atribuya esa condición al objeto de subsumir los hechos en el artículo 319.1 CP”.

A pesar de ello, lo llamativo de esta sentencia reside en que, a pesar de aceptar el citado argumento referido a la retroactividad de una ley extrapenal más favorable que integra el artículo 319.1 CP, los mismos hechos no quedan impunes sino que son subsumidos en el apartado $2^{\circ}$ de este mismo precepto. Y ello porque se entiende que el delito allí previsto podría ser aplicable "sin producir indefensión al acusado, ni infringir el principio acusatorio, por tratarse de un precepto de idéntica estructura técnica, en el que se identifican en sus núm. $1^{\mathrm{o}}$ y $2^{\circ}$, los autores (promotores, constructores o técnicos directores), las obras que atacan la ordenación del territorio (urbanización, construcción o edificación), situándose la única diferencia en la naturaleza de los terrenos a los que afecta la conducta delictiva, que ha sido objeto de la más amplia contradicción". En definitiva, el TS aprecia parcialmente el motivo estableciendo que el artículo 319.2 CP resulta plenamente aplicable "porque la Orden 903/2001 de la Comunidad de Madrid, que solo inicia un procedimiento de declaración de zona de especial protección, pero en previsión de que la misma, hasta tanto se declare sea objeto de modificaciones o 
transformaciones físicas o biológicas, que impidan surtir plenos efectos o conseguir los objetivos del Plan, señala unas claras disposiciones en su apartado $2^{\circ}$, según el cual se declara la zona como no urbanizable, resultando prohibido el otorgamiento de ninguna autorización, licencia o concesión, que habilite para la realización de actos de transformación física o biológica sin informe favorable de la Consejería". Por todo ello se entiende que el recurrente, a pesar de tales prohibiciones realizó movimientos de tierras, sin informar al Ayuntamiento, ni obtener la correspondiente licencia de tal Ayuntamiento o de la Consejería realizando los actos prohibidos. A efectos prácticos, la subsunción de los hechos en el artículo 319.2 CP comporta la aplicación de unas penas inferiores para el delito por el que se le condena en la sentencia recurrida y casada por el TS. Así pues, finalmente, se dicta una segunda sentencia en la que se condena al acusado como autor de un delito consumado contra la ordenación del territorio (artículo 319.2 $\mathrm{CP})$, sin la concurrencia de circunstancias modificativas a la pena de 1 año de prisión, con las accesorias correspondientes, multa de 15 meses con una cuota diaria de 6 euros, y a la inhabilitación profesional correspondiente y realización de obras de restauración establecidas en la sentencia de instancia.

La segunda sentencia que merece un detenido comentario es la STS núm. 752/2016, de 11 de octubre. En ella se resuelve el recurso de casación contra la sentencia recaída en un caso de prevaricación instruido por el Juzgado de Instrucción ( $\left.\mathrm{n}^{\circ} 1\right)$ de Granollers y sentenciado por la Audiencia Provincial de Barcelona. En la sentencia de instancia se condenó a dos acusados: de un lado, a Marcos, arquitecto Municipal del Ayuntamiento de Les Franqueses del Vallès. Básicamente, porque informó hasta en tres ocasiones la solicitud de licencia municipal de obras mayores presentada en fecha 19.02.2008 por Angélica en representación de la empresa Mercadona. Las dos primeras veces informó desfavorablemente, pero la tercera vez informó a favor de dicha licencia, aunque sin poner de manifiesto que no era posible su concesión al prohibirlo varias normas municipales (artículo 206 del Plan General de Ordenación Municipal, el Plan Parcial del Sector U del término Municipal de Les Franqueses del Vallès, y el artículo 14.2 del Plan Territorial Sectorial d'Equipaments Comercials). Constaba probado que era conocedor de que la normativa citada no permitía las actividades comerciales ajenas al uso industrial en el solar en el que se proyectaba la edificación. Además -según aquella sentencia- el acusado informó favorablemente la concesión de la licencia de obras mayores sin que se hubiese obtenido previamente la licencia de actividades, pese a saber que, conforme a lo 
dispuesto en el Decreto 179/2005 que aprueba el Reglament d'Obres, Activitats i Serveis dels Ens Locals de Catalunya (artículo 77.4), era preciso la obtención previa o simultánea de dicha licencia de actividades. Por estos hechos probados Marcos fue condenado como autor de un delito contra la ordenación del territorio penado en el artículo 320.1 del C.P., a la pena de multa de 12 meses.

Por otra parte, la sentencia de instancia también condena al secretario de ayuntamiento del mismo municipio, sobre la base de que venía obligado a emitir informe jurídico en el expediente de licencia de obras mayores, (conforme al Texto Refundido de la Llei d'Urbanisme de Catalunya) al carecer el citado ayuntamiento de servicios jurídicos. Constaba acreditado que pese a tener conocimiento de su obligación de informar, incumplió la misma siendo conocedor de que su otorgamiento era imposible por contravenir abiertamente la normativa urbanística aplicable y que no se había concedido la licencia de actividades. Concretamente el 28 de marzo de 2008, el arquitecto y jefe de obras del Servei de Medi Ambient del ayuntamiento, emitió informe mediante el cual se denegaba la compatibilidad interesada por no estar la actividad de supermercado de alimentación directamente relacionada con el desarrollo de una actividad industrial. No obstante, el acusado certificó el anterior informe, en la misma fecha 28 de marzo de 2008, que se consideró “erróneo" por cuanto no había tomado posesión en el Ayuntamiento hasta el día 14 de abril. Es decir, el acusado suscribió otro informe en el que hizo constar la misma fecha, 28 de marzo de 2008, certificando la existencia de un informe a tenor del cual la actividad de supermercado de alimentación con zona de aparcamientos a instalar en la Calle (...) era compatible con el planeamiento urbanístico vigente, sin que ese informe en realidad existiese. Por estos hechos, el secretario del ayuntamiento fue condenado como autor responsable de un delito de falsificación, previsto y penado en el artículo 398 del C.P. en concurso medial con un delito contra la ordenación del territorio del artículo 320.1 del C. en comisión por omisión, sin la concurrencia de circunstancias modificativas de la responsabilidad criminal, a multa de 12 meses de prisión.

En el análisis del recurso interpuesto por el primer acusado, Marcos, el TS rechaza cualquier vulneración del derecho a la presunción de inocencia $\left(\mathrm{FJ} 1^{\circ}\right)$. Ahora bien, estima el motivo del recurso de casación concerniente a la denuncia de un error en la apreciación de la prueba (artículo 849.2 ${ }^{\circ}$ de la LECRIM), enfocando su análisis en el propio informe que se reputaba constitutivo de la prevaricación. El recurrente sostenía que su contenido íntegro debía figurar en los hechos probados, dada su relevancia a los efectos de 
valoración de su conducta. Y, en efecto, el TS admite dicho informe íntegro sobre la base de que en dicho informe-propuesta constaba de modo claro que "la licencia de obras, cuya concesión se propone, no supone la autorización de ningún tipo de actividad y que ésta queda condicionada a la obtención de la licencia ambiental, de donde resulta que se constata que ésta aún no ha sido concedida y que la actividad pretendida no podrá iniciarse hasta obtenerla". Así pues, el TS determina que "el contenido íntegro del documento resulta relevante en cuanto al alcance de la licencia de obras en el caso, sin perjuicio de lo que se diga más adelante en cuanto a la posibilidad de conceder esta licencia, aunque no se dispusiera aún de la correspondiente licencia de actividad". En consecuencia, con este razonamiento, estima el motivo e incorpora el informe a los hechos declarados probados $\left(\mathrm{FJ} 2^{\circ}\right)$.

Otro importante motivo aducido por el mismo recurrente fue la infracción, por inaplicación indebida del artículo 320.1 CP (artículo 849.1 LECRIM). En opinión del recurrente, él no tenía obligación de informar acerca de la normativa urbanística relativa a los usos autorizados, pues ese aspecto era competencia de otro departamento y además indicó que la concesión de la licencia de obras no suponía la autorización de ninguna actividad. Entendía, por tanto, que la edificación, en cuanto tal, no era manifiestamente ilegal y que su conducta había sido "neutral". A este respecto el TS destaca el concepto de prevaricación que debe manejarse en relación con el delito del artículo 320 CP. Es importante indicar que en esta sentencia se acoge un entendimiento del mismo, según el cual, existe una relación entre el delito de prevaricación del artículo 404 y el de la llamada prevaricación urbanística del artículo 320. Y aunque ambos compartan aspectos comunes relativos al bien jurídico, condición de autor o al concepto de arbitrariedad y a la actuación "a sabiendas de la injusticia", también se señalan algunas diferencias. Con todo, en esta resolución el TS apela a resoluciones anteriores (en concreto a la STS núm. 497/2012, de 4 de junio), para determinar que es doctrina asentada el entendimiento según el cual, el delito del artículo $320 \mathrm{CP}$, es una prevaricación especial por razón de la materia sobre la que se realiza, aclarando que la misma se refiere a la normativa urbanística. A partir de este razonamiento - al que se podrían realizar diversas matizaciones que no corresponde ahora indicar, para no extendernos-, el TS llega a destacar dos importantes aspectos en el caso enjuiciado. Por una parte, recuerda que el suelo donde se pretendía realizar la construcción estaba clasificado como urbano y calificado como industrial. "Era pues, posible construir, con los límites establecidos por las normas vigentes en la materia. Pero, 
como se declara probado en la sentencia, solo era posible destinar las edificaciones a usos comerciales que estuvieran directamente relacionados con el desarrollo de la zona industrial" $\left(\mathrm{FJ}^{\circ}{ }^{\circ}\right.$. Por otra parte, determina que en el caso enjuiciado, era necesaria no solo la licencia de obras, sino también la licencia de actividad, que son autorizaciones diferentes y contemplan aspectos distintos. Asimismo, destaca que la normativa vigente dispone con carácter general que la licencia de obras no deberá ser concedida antes de que lo sea la de actividad (véase, artículo 22.3 del Reglamento de Servicios de las Corporaciones Locales de 1955). Además, se señala que, para la concesión de la licencia de actividad ambiental, la normativa vigente en Cataluña disponía que era necesario unir al expediente, entre otra documentación, un certificado de compatibilidad urbanística, al que se hace referencia concreta y detallada en la sentencia y que fue suscrito, como ordena la legislación aplicable, por el secretario del ayuntamiento, con el visto bueno del alcalde. Y por último se recuerda que ya en la sentencia impugnada se advierte que existían en el caso dos expedientes independientes, uno de actividades y otro de obras mayores, relativos cada uno de ellos a la correspondiente licencia, así como de dos concejalías con competencias separadas sobre una y otra clase de licencias. A la vista de estos aspectos el TS dictamina que "el recurrente, de un lado, no modificó sin razones su informe desfavorable, sino que lo emitió finalmente en sentido favorable a la concesión de la licencia de obras en vista del escrito de renuncia presentado por la parte solicitante, y expresando en su propuesta que la concesión de la licencia no autorizaba a instalar ninguna actividad, la cual quedaría condicionada a la obtención de la correspondiente licencia ambiental de actividad. Y, de otro lado, que su decisión de no informar en el expediente de la licencia de obras acerca de los aspectos relacionados con los usos a los que se dedicaría la edificación pretendida, no fue arbitraria en el sentido de frontal e irracionalmente contraria a las normas y a su correcta interpretación, en tanto que ese concreto aspecto de la cuestión, es decir, la relativa a si los usos pretendidos eran conformes a la normativa vigente, iba a ser objeto de atención específica al tramitar la solicitud de la licencia de actividad, a cuya obtención quedaba condicionado el inicio de la misma". Por todo lo cual, finalmente, el TS estima el motivo aducido por el recurrente Marcos, sin considerar necesario seguir examinando las demás cuestiones planteadas por el mismo en la sentencia.

Con respecto al otro recurrente, secretario del ayuntamiento, el TS estima parcialmente su recurso de casación. De modo que en relación con la condena que se le había impuesto 
por un delito de falsificación de certificados del artículo 398 en concurso medial con un delito contra la ordenación del territorio del artículo $320.1 \mathrm{CP}$, se modifica en parte su condena. A este respecto el TS desestima el motivo que denunciaba infracción por aplicación indebida del artículo 398 CP (artículo 849.1 LECRIM) por inexistencia de elemento subjetivo en la falsedad. Sin embargo, estima parcialmente el motivo que denunciaba la infracción del artículo $320.1 \mathrm{CP}$ por no concurrir los elementos objetivo y subjetivo del tipo (FFJJ $4^{\circ}$ y $5^{\circ}$ ). Con respecto a este último motivo, conviene reparar en que el recurrente había sido condenado como autor de un delito del artículo 320.1 CP, en comisión por omisión, al entenderse que había omitido el informe preceptivo en el expediente de la licencia de obras, en la medida en que debía haber puesto de relieve que los usos permitidos en el suelo no autorizaban la actividad que se pretendía desarrollar por el solicitante. En cuanto a la omisión de ese informe en la tramitación de la licencia de obras, entiende el TS que en realidad se debía dilucidar la compatibilidad de la actividad con la normativa en vigor, pero a través de otro informe, denominado de compatibilidad urbanística que emitía otro arquitecto en otro expediente (el relativo a la solicitud de licencia ambiental de actividad). Por consiguiente, el TS viene a desmontar el argumento de que existió una omisión con relevancia penal, al entender que "no era necesario informar sobre esos extremos en el expediente de la licencia de obras. En consecuencia, carece de relevancia penal la omisión del informe preceptivo en ese expediente por parte del recurrente". Por ello, en definitiva, se estima el motivo segundo referido a la infracción del artículo 320.1 CP por aplicación indebida del delito allí previsto.

A la vista de todo lo anterior, finalmente, el TS declara haber lugar al recurso de casación del primer recurrente, arquitecto municipal (Marcos) y estima parcialmente el recurso del segundo recurrente, secretario de ayuntamiento. En consecuencia, se dicta una segunda sentencia, en la que se absuelve a cada uno de ellos del delito contra la ordenación del territorio (artículo 320.1 CP) por el que habían sido condenados, manteniendo los demás pronunciamientos de la sentencia de instancia no afectados por esta última.

Al margen de estas dos relevantes sentencias del TS, ha de reseñarse que recientemente ha recaído una de las primeras sentencias en que se enjuicia la posible responsabilidad penal de una persona jurídica conforme a lo previsto en el apartado $4^{\circ}$ del artículo 319 CP. En este sentido, conviene analizar brevemente la SAP de Barcelona núm. 578/2016, de 26 de julio. Con respecto enjuiciamiento de la novedosa previsión de la 
responsabilidad penal de una empresa operante en el ámbito urbanístico, conviene destacar que, en primera instancia, se condena a una persona jurídica (la mercantil, Torracs SL) a la vez que también se condenan a dos personas físicas: Fausto, responsable de la construcción y Carmelo, administrador de aquella empresa. La condena recaída en primera instancia, les aplica, correspondientemente, las previsiones de los artículos 319.1, 3 y 4 CP. No obstante, el aspecto más importante de esta resolución fue concretar el momento de realización de las obras, para así determinar si era de aplicación al supuesto de hecho la regulación penal introducida por LO 5/2010, de 22 de junio, que, en la sentencia, se considera norma penal más gravosa a efectos de analizar su aplicación retroactiva. A este respecto la Audiencia dictamina que "la fecha de la construcción no puede concretarse, aunque tenemos la certeza y acreditación de que es posterior a agosto de 2008, ya que en esa fecha era inexistente y cuando fue paralizada estaba como en noviembre de 2011, esto es el edificio había cubierto aguas pero estaba inacabado, y se trata de una obra permanente adherida al suelo y sin posibilidad de traslado; no es algo móvil o desmontable o transportable, sino que es una construcción permanente y fija. Es una obra no insignificante, con vocación de ser utilizada con los elementos constructivos, estéticos y de habitabilidad para considerarlo 'edificio' e incluso 'vivienda', como efectivamente pretendían los acusados, pues pensaban destinarlo a ese uso de vivienda familiar" (FJ 5 $5^{\circ}$. Es interesante destacar que las citadas obras se consideran "no autorizables" por el tribunal de modo que se entiende que se trata de "una infracción urbanística que tendría la naturaleza de 'no autorizable' si adolece de irregularidades tan graves y escandalosas que ni siquiera cabe la posibilidad de una posterior subsanación ni legalización, ni autorización ni convalidación aunque se pida licencia, o dicha 'legalización' sería remota, futura e incierta”. La Audiencia no encuentra ninguna falta de prueba a este respecto. Mas admite el motivo referente a la irretroactividad de la regulación penal de la citada LO 5/2010 que introduce, por primera vez en nuestro país, la responsabilidad penal de las personas jurídicas. A este respecto, se dictamina que "respecto a la tipicidad, se alega error en el marco normativo y la aplicación temporal de la norma penal, pretensión que debe prosperar pues ciertamente los hechos probados evidencian que la construcción se realiza en el curso del año 2010 y la LO 5/2010 de 22 de junio entró en vigor el día 23 de diciembre de 2010. Por lo tanto, en un discurso lógico y razonable, hemos de colegir que la obra se inició antes de la entrada en vigor de dicha LO 5/2010 y por ello es de aplicación la normativa anterior y vigente hasta la entrada en vigor, que contiene normas más beneficiosas, y además impedir la condena de la persona 
jurídica Torracs SL, toda vez que en la responsabilidad de la persona jurídica se tipifica por vez primera en la citada LO 5/2010, sin perjuicio de responder, en caso de ser necesario, como responsable civil subsidiario de los gastos y responsabilidad civil que puedan generarse derivados de la demolición de la obra, que analizaremos en un momento posterior" $\left(\mathrm{FJ} 8^{\circ}\right)$. Es importante indicar que pese a que la Audiencia ratifica la absolución de la persona jurídica (FJ $9^{\circ}$ ), mantiene la condena de las personas físicas, si bien modificando la pena a imponer, conforme a la regulación anterior a la reforma introducida por LO 5/2010 (FJ 10). Respecto del responsable de la construcción (Fausto) se entiende que "su autoría es clara y evidente, sin que pueda alegarse desconocimiento de la normativa por las razones ya expuestas". En relación con el otro recurrente, Carmelo, se considera que "era el administrador de la entidad Torracs SL y no pudo quedar al margen de la cesión del terreno para la construcción de dicha obra ilegal, que iba a disfrutar su hija, quien es la mujer del Sr. Fausto. La tesis planteada supone que la casa apareció de forma sorpresiva y sin ellos imaginarlo resultó ilegal, pero la situación real fue muy distinta, remitiéndonos nuevamente a lo ya dicho. Ambos recurrentes actuaron de consuno y ambos deben responder penalmente" (FJ 10 ). Al ser condenados conforme al artículo 319.1 CP, anterior a la reforma operada por LO 5/2010, la pena que se les impone en la segunda sentencia es, para cada uno de ellos, más atenuada, consistiendo, básicamente, en prisión de seis meses. Precisamente porque se mantiene esta condena, llama la atención que, finalmente, la Audiencia decida diferir la imposición de la medida de demolición de las obras del artículo 319.3 CP, dejando pendiente su resolución hasta que recaiga sentencia firme en la jurisdicción contencioso-administrativa, "pues es factible que la no demolición sea la respuesta adecuada para el caso de que finalmente dicho organismo sí autorizara la edificación realizada". Para ello, la Audiencia conceptúa la demolición como una medida de restitución en el ámbito de la responsabilidad civil de carácter potestativo. De modo que para diferir su imposición, apela al artículo 115 del $\mathrm{CP}$, que "brinda un instrumento coherente con este planteamiento, cual es el de diferir a la ejecución de la sentencia la decisión de dicho extremo" (FJ 11º). 


\section{Delitos contra los recursos naturales y el medio ambiente}

Con relación a los delitos contra los recursos naturales y el medio ambiente, en el período de referencia de esta crónica no se han dictado un gran número de resoluciones judiciales. De las seis susceptibles de ser comentadas, tres se refieren a un supuesto de contaminación acústica, confirmándose una vez más el carácter predominante de esta modalidad de contaminación en la jurisprudencia penal sobre el delito ecológico.

La primera sentencia que trata un supuesto de contaminación acústica es la SAP de Barcelona (Sección 8a) núm. 211/2016, de 8 de abril. Con relación al tipo objetivo, la sentencia afirma la capacidad de una ordenanza municipal para integrar la norma penal en blanco, consolidando así la línea jurisprudencial comentada en crónicas anteriores. En el mismo sentido, se pronuncia otra de las sentencias comentadas más abajo, relativa a un supuesto de vertidos: "El texto legal da cabida a legislación que resulte aplicable en el Estado Español, ya sea comunitaria, estatal, autonómica o local, e incluye la que surge a partir de los tratados internacionales suscritos por España y que, de conformidad con lo dispuesto en el artículo $96 \mathrm{CE}$ y $1.5 \mathrm{CC}$ pasan a formar parte del ordenamiento jurídico español” (SAP de Castellón núm. 67/2016, de 2 de marzo).

En cuanto a las vías de producción del ruido, la sentencia de la Audiencia Provincial de Barcelona admite tanto las vías directas como las indirectas "abarcando así un amplio espectro de conductas, desde aquellas que por sí solas sean emisoras de ruidos como las actividades que solo de manera tangencial los produzcan”. En este caso, los hechos probados se refieren al impacto de los ruidos producidos por la actividad de una residencia de ancianos sobre la salud de los moradores de la vivienda contigua.

Sin embargo, la sentencia es absolutoria al considerar que no concurre dolo "por ser evidente que la conducta del acusado tenía por finalidad el desarrollo de una actividad industrial y no la pura intención de causar el efecto lesivo, es decir crear una situación de riesgo grave o directamente menoscabar la salud de los moradores de la vivienda contigua. Pero es que además, ha resultado acreditado que no permaneció impasible ante las quejas y denuncias de los querellantes, si no que por el contrario fue adoptando medidas correctoras a medida que iba teniendo conocimiento del resultado lesivo causado por su actividad empresarial e intentó tomar nuevas medidas cada vez que un estudio sonométrico ponía de manifiesto la falta de eficacia de las anteriores, sin que hubiese logrado que cesasen las emisiones precisamente ante la actitud obstaculizadora de los querellantes quienes no le permitieron realizar en su domicilio las pruebas que hubiesen 
podido señalar con la necesaria seguridad y certeza las fuentes de transmisión del ruido". La segunda sentencia relativa al delito de contaminación acústica del período que abarca esta crónica, es la STS núm. 370/2016, de 28 de abril. En esta ocasión el Tribunal Supremo anula la sentencia de primera instancia, que condenó al acusado por un delito de contaminación acústica sin la concurrencia de modalidades agravadas, y dicta segunda sentencia condenando por un delito de contaminación acústica con aplicación de la agravación de riesgo de grave perjuicio para la salud de las personas.

El Tribunal Supremo fundamenta la segunda sentencia en el error de derecho apreciado en la resolución recurrida, la cual no aplicaba debidamente el tipo penal contra el medio ambiente como un delito de peligro hipotético, de peligro abstracto/concreto o de aptitud, sino como un delito de resultado. Así, en primera instancia se había descartado la apreciación de la modalidad agravada basándose en que si bien la médico forense había ratificado en el juicio los efectos del ruido sobre la salud y, en concreto, sobre el tipo de patología neuro-degenerativa reactiva que sufría la denunciante, había igualmente reconocido que nunca pudo valorar personalmente esa crisis y esa sintomatología por el propio estado en que se encontraba la paciente, y sólo pudo hacerlo a través de las manifestaciones de sus familiares. El Tribunal Supremo recuerda, con base en la doctrina, que lo característico de los delitos de peligro hipotético es que basta un comportamiento idóneo para producir un peligro para el bien jurídico, sin necesidad de que éste se materialice en un resultado de peligro concreto o en una lesión del mismo. Cita además jurisprudencia referente a supuestos similares en los que llegó a afirmarse que "no es preciso que el médico forense llegue a observar o explorar a las presuntas víctimas, puesto que es sabido y por lo tanto público y notorio que una larga exposición a ruidos perturbadores del sueño entraña un riesgo de grave perjuicio para la salud de las personas (STS núm. 327/2007, de 27 de abril)”, así como aquella jurisprudencia por la que se establece "que el medio ambiente protegido es también el hábitat de una o varias personas, es decir, el conjunto local de condiciones geofísicas en las que se desarrolla la vida de una especie o de una comunidad animal o de personas", por lo que "el sujeto pasivo del delito contra el medio ambiente no se caracteriza por el alto número de perjudicados, sino por la pertenencia a la especie cuya base biológica se desarrolla en el mismo (SSTS núm. 327/2007, de 27 de abril y núm. 152/2012, de 2 de marzo)”.

Esta sentencia plantea además la cuestión de la ley aplicable en el tiempo. El Tribunal Supremo considera que la sentencia recurrida incurre en "una patente contradicción", 
pues si bien al inicio considera que es de aplicación el texto legal vigente en el momento de comisión de los hechos (esto es, la redacción anterior a la LO 5/2010, de 22 de junio), finalmente opera con el texto legal vigente, introducido por la LO 1/2015, sin aportar ningún tipo de razonamiento que justifique el cambio de criterio. En la medida que las penas implantadas por la reforma de 2015 son superiores a las previstas en el texto legal vigente en el momento de los hechos, el Tribunal Supremo estima que debe de ser de aplicación el texto legal anterior.

Todavía con relación al delito de contaminación acústica, resulta de interés dejar constancia aquí del AAP de Jaén (Sección 2ª) núm. 358/2016, de 17 de mayo. El interés de esta resolución judicial no radica tanto en la interpretación del tipo penal sino en una cuestión de índole procesal de indudable trascendencia práctica. La cuestión suscitada se refiere a la posible reapertura de diligencias como consecuencia de la revocación de una licencia en la jurisdicción contencioso-administrativa, por considerarse que ésa última arroja los indicios incriminatorios que faltaban en el momento del sobreseimiento. Mientras el Juez Instructor, sin previo traslado a las partes, dictó auto acordando no haber lugar a la reapertura de las actuaciones al no haberse aportado hechos nuevos sino resoluciones judiciales dictadas en el devenir del proceso contencioso-administrativo incoado, el Tribunal Supremo estima el recurso de apelación interpuesto y ordena la reapertura de las diligencias afirmando que "no puede aceptarse la resolución del Juez Instructor que considera que no son hechos nuevos sino resoluciones judiciales derivados de un proceso contencioso-administrativo, en tanto los informes técnicos de la arquitecta y la sentencia, con fechas posteriores al auto de archivo provisional, vienen a poner de manifiesto que la actividad iniciada por los titulares del bar era presuntamente contaminante".

En el ámbito de los vertidos, la ya citada SAP de Castellón (Sección 1ª) núm. 67/2016, de 2 de marzo, analiza la conducta típica recordando algunos aspectos puestos de relieve por el Tribunal Supremo. Así, la posibilidad de comisión por omisión (dejar que se produzca la emisión o vertido y no poner los medios para evitarla) o la diferencia de significado entre los dos verbos nucleares "provocar" y "realizar". En este sentido, recuerda: "El Tribunal Supremo ha interpretado (entre otras, SSTS núm. 105/1999, de 27 de enero; núm. 96/2002, de 30 de enero; y núm. 81/2008, de 13 de febrero) que provocar en su diferencia con realizar se refiere a mantener emisiones o vertidos. La interpretación contextual da pie para ello al concretar que el vertido puede hacerse directa o 
indirectamente y no sólo en el sentido subjetivo o personal, sino en el objetivo, finalista o direccional. Pretende de esta manera abarcar toda acción humana que determine un vertido contaminante de modo directo o indirecto. En la misma línea la jurisprudencia ha identificado como vertido la introducción de sustancias contaminantes. Además de los vertidos directos, es decir aquellos que provocan que el elemento que contamina se introduzca sin intermediaciones en la atmósfera, el suelo o el agua, ha considerado como vertidos indirectos incluidos en el tipo previsto en el artículo $325 \mathrm{CP}$ conductas que, si bien no determinaron una evacuación directa, integraron un comportamiento previo del que necesariamente habría de derivarse ese vertido".

Una de las cuestiones a destacar de esta sentencia es que considera probada la infracción de la normativa ambiental a través de la acreditación de la inexistencia de la licencia municipal de autorización de funcionamiento, exigida por la normativa vigente. Acogiéndose a esta posibilidad interpretativa sorprende que no se plantee el rechazo de la circunstancia agravante de clandestinidad por la vulneración que ello supondría del principio ne bis in idem, sino únicamente por considerar que, en el caso enjuiciado, la actividad no es oculta o secreta.

Con relación al tipo subjetivo, aplica la línea jurisprudencial según la cual "la contaminación por vertidos (STS núm. 1538/2002, de 24 de septiembre) no requiere una específica construcción dolosa, sino la genérica del dolo, esto es, conocimiento de los elementos típicos y la voluntad de su realización, habiendo rechazado la jurisprudencia la calificación imprudente cuando se está en presencia de un profesional, conocedor de la carga tóxica transportada, de la necesidad de autorización administrativa, de su procedencia y de la gran cantidad de aquélla (STS núm. 442/2000, 13 de marzo). En estas situaciones si bien no es deducible una intencionalidad de perjudicar al medio ambiente o de crear un riesgo, las reglas de la lógica, de la experiencia y del recto juicio permiten asegurar que el agente es consciente de esas eventualidades y, pese a ello, realiza la acción”. Tratándose de un delito de peligro hipotético, la sentencia todavía especifica que “el elemento subjetivo del dolo no ha de ir referido a una situación que ya haya dado lugar a la concreción del peligro, y menos aún al daño efectivo, sino al comportamiento y a su idoneidad para generar aquella situación (STS núm. 141/2008, de 8 de abril )”.

Finalmente, con relación a la circunstancia agravante específica de desobediencia del artículo 326 b) del CP (hoy en el artículo 327), esta sentencia recuerda que "es unánime la doctrina jurisprudencial cuando establece los requisitos que han de exigirse para su 
apreciación: el requerimiento ha de ser expreso y debe contener la orden de suspender o corregir las actividades que se están desarrollando; debe ser emitido por la autoridad administrativa competente en materia de medio ambiente para ordenar la corrección o suspensión de las actividades perjudiciales; y es necesario, obviamente, el conocimiento de la orden por parte del sujeto activo del delito y su voluntad manifiesta de incumplirla". Con relación a lo que deba entenderse por órdenes expresas añade que "no serán tales las meras sugerencias o recomendaciones que la autoridad administrativa haya podido formular, debiéndose excluir también las indicaciones tácitas, presuntas o genéricas. El término 'expresas' debe interpretarse con arreglo a la normativa administrativa, de manera que hemos de entender que el acto administrativo que contiene la orden debe haberse producido siguiendo el procedimiento adecuado, ha de ser motivado y escrito".

Otra de las sentencias dictadas en este período, es la STS núm. 463/2016, de 31 de mayo. Esta sentencia se refiere a la actividad desarrollada en una mercantil dedicada al tratamiento de frigoríficos y aparatos de frío una vez terminada su vida útil, para la que se contaba con una autorización de gestor de residuos peligrosos de aparatos eléctricos y electrónicos. La sentencia de instancia declara probado que buena parte de los frigoríficos no eran tratados adecuadamente, produciéndose como consecuencia la emisión a la atmósfera de un mínimo de 54.537,262 kilos de gases CFC destructores de la capa de ozono, equivalentes a una emisión en C02 de 174.511.954 kilos. Con base en ello, condena por un delito contra el medio ambiente y los recursos naturales al administrador único del grupo empresarial al que pertenecía la mercantil, así como a quien actuaba como encargado de planta de esa empresa controlando las operaciones. La sentencia de primera instancia condena a los acusados a dos años y un año de prisión respectivamente, con multa de 12 meses con una cuota de 50 euros al día en el primer caso y de 8 meses con una cuota de 7 euros en el segundo, a la accesoria de inhabilitación especial para el derecho de sufragio pasivo durante el tiempo de la condena en ambos casos y a la pena de inhabilitación especial para el ejercicio de la profesión de gestor de residuos por tiempo de tres y un año también respectivamente. La condena es confirmada por el Tribunal Supremo.

En la medida que el recurso se orienta principalmente a cuestionar la valoración de la prueba, la sentencia del Tribunal Supremo no entra a analizar a fondo los elementos del delito. No obstante ello, el Tribunal Supremo se pronuncia sobre una cuestión de indudable interés como es la no necesidad de determinación exacta de la cuantía de las 
emisiones para la acreditación de la concurrencia de los elementos típicos. Así, afirma: "La determinación exacta del gas contaminante emitido a la atmósfera constituye una cuestión de prueba compleja, como razona el Ministerio Fiscal, pues los gases que se dejaron escapar solo pueden ser medidos por procedimientos indirectos, y mediante cálculos aproximados, que difícilmente pueden llevar a una conclusión exacta. Pero en realidad esta determinación no es necesaria para el tipo, pues la prueba testifical practicada ya ha determinado que los acusados provocaron vertidos de gases contaminantes a lo largo de cuatro años y que estos vertidos procedían de un número muy elevado de los aparatos frigoríficos sometidos a tratamiento (la mayor parte, dicen los testigos, aproximadamente un 60 o 70\%). Dada la elevada peligrosidad de estos gases para la capa de ozono, puede estimarse que unas emisiones continuadas de gases CFC altamente contaminantes durante varios años constituyen indudablemente un peligro potencial para el equilibrio de los sistemas naturales".

La última resolución a comentar es la STS núm. 516/2016, de 13 de junio. Los hechos se refieren a la actividad de una cantera de piedra caliza explotada a cielo abierto desde el año 1968, asentada en terrenos clasificados como suelo rústico de protección forestal, en un paraje situado en la zona periférica de protección del Espacio Natural de las Médulas y comprendida dentro de la cuenca visual percibida desde el conocido como mirador de Orellán. Dicha cantera se sitúa además a la altura de la mitad del curso del conocido como arroyo Balado que, con un recorrido de unos 3,5 Km, nace en el Lago de Carucedo y desemboca en el embalse de Peñarrubia.

De acuerdo con los hechos probados, la actividad desarrollada: a) supuso una severa afectación paisajística para el entorno natural en el que se asientan la cantera y sus instalaciones; b) incidió negativamente en la flora y la fauna de los terrenos; c) ocasionó una anómala acción erosiva del suelo notoriamente acrecentada por el movimiento de tierras y d) afectó a los organismos que forman parte del arroyo Balado, como consecuencia del impacto del arrastre por el aire y el agua de los sedimentos generados por la actividad, sobre el lecho y la profundidad de su cauce. La actividad en la cantera se desarrollaba sin sujeción a procedimiento de evaluación de impacto ambiental y sin licencia ambiental.

La sentencia de primera instancia condena a quien desde 1997 era consejero delegado de la empresa por un delito contra el medio ambiente y los recursos naturales, a las penas de cuatro años y un día de prisión con la accesoria de inhabilitación para el ejercicio del 
derecho de sufragio pasivo durante el tiempo de la condena; multa de veinticuatro meses y un día con una cuota diaria de diez euros e inhabilitación especial para profesión u oficio durante tres años y un día. Así mismo, le condena a satisfacer la cantidad de 475.000 euros, a disposición de la Consejería de Medio Ambiente de la Junta de Castilla y León, para llevar a cabo actuaciones de restauración. La sentencia absuelve del delito de prevaricación ambiental a quien era alcalde del Ayuntamiento de Carucedo.

El principal interés de esta sentencia radica en las cuestiones suscitadas en torno a la responsabilidad penal de las personas jurídicas. El recurrente sostiene que el autor del delito no es él sino la persona jurídica y que la responsabilidad declarada en la sentencia es por su condición de representante legal de la misma siendo ésta la que debió haber sido imputada por la conducta típica. Sin embargo, el Tribunal Supremo desestima el motivo al considerar que "al tiempo de la comisión de los hechos, -de junio de 1997 a febrero de 2009- no se había promulgado el precepto penal que denuncia como inaplicado. Concretamente la responsabilidad penal de las personas jurídicas. Consecuentemente, tampoco existió una responsabilidad penal imputada a la persona jurídica desde la acusación y tampoco esa responsabilidad formó parte del objeto del proceso. Además, aún en el supuesto de que, salvadas las exigencias derivadas del principio de legalidad y del acusatorio, se hubiera ejercido la acción penal contra la persona jurídica, la redacción del precepto, no excluye la de la persona física que la representa si concurren en él los elementos de la autoría precisos para la imputación y la subsunción de su conducta en la norma".

Aunque el Tribunal Supremo no considere aplicable al caso la redacción vigente del artículo 31 bis $\mathrm{CP}$, contribuye con esta sentencia a la interpretación del régimen de responsabilidad penal de las personas jurídicas, sobre el que todavía hay escasa jurisprudencia. Así, insiste: "El artículo 31 bis del Código penal actúa como una cláusula de determinación de la autoría definitoria del tipo de autor en las personas jurídicas. El artículo 31 bis señala los presupuestos que han de concurrir para la declaración de persona jurídica como autora del delito, esto es, un delito cometido por persona física representantes legales o por empleados - en nombre o por cuenta de una persona jurídica o en el ejercicio de las actividades sociales por cuenta o en beneficio directo o inmediato de la persona jurídica, y que por ésta no han adoptado las medidas de organización y gestión necesarias, que incluyen medidas de vigilancia y control de los posibles resultados típicos que el ejercicio de su actividad de la persona jurídica pueda realizar. En el diseño 
de esta imputación a título de autor del delito a la persona jurídica, el legislador ha optado por un sistema vicarial, siendo independiente la responsabilidad penal de la persona física y de la jurídica (artículo 31 ter CP), respondiendo cada una de ellas de su propia responsabilidad".

Justamente es la idea de sistema vicarial, la que servirá también para desestimar el motivo por el cual el recurrente alega la no aplicación del precepto penal más favorable. Mientras el recurrente considera que la nueva previsión legal de la responsabilidad penal de las personas jurídicas es más favorable, el Tribunal Supremo insiste en que "la previsión de una responsabilidad penal de la persona jurídica no es excluyente respecto de la persona física, sino que para el código es acumulativa, pudiendo darse ambas responsabilidades conjuntamente".

Con relación a la agravante de clandestinidad, el recurrente sostiene la necesidad de interpretar de forma restrictiva el tipo agravado, añadiendo que la actividad industrial era conocida por parte de la Administración desde 1968. El Tribunal Supremo recuerda la jurisprudencia que niega la equiparación de la clandestinidad con la idea de funcionamiento oculto y centrándose en la idea de funcionamiento sin la autorización o aprobación administrativa, recuerda que durante al menos diez años en los que el recurrente era consejero delegado de la empresa, ésta actuó sin licencia y sin evaluación del impacto ambiental. Y añade: "El hecho de que la industria dispusiera de una autorización temporal para el desarrollo de su industria no empece a la exigencia de la licencia con el previo estudio de impacto que es una exigencia posterior al inicio de la actividad y que aparece impuesta por el Decreto 101/2002 dictado en desarrollo de la Ley 8/199_de la Comunidad Autónoma y a la que la empresa debió sujetar su actividad y que no solicitó sino hasta el año 2007 ”.

Así mismo, el Tribunal Supremo niega la apreciación de un supuesto de error (que el recurrente no concreta si de tipo o de prohibición) "al tratarse de una industria sometida a unas especiales exigencias de control de riesgo por tratarse de una actuación arriesgada que desarrolla su función en un parque especialmente protegido que obliga a extremar las cautelas y exigencias para asegurar lo que la norma trata de prevenir. No cabe argüir desconocimiento de la norma cuando la actividad que se desarrolla, precisamente por la situación de riesgo que comporta, exige conocer el ámbito de lo permitido”.

Finalmente, con relación a esta sentencia resulta cuando menos curiosa la alegación de vulneración del principio de igualdad por parte del recurrente por el hecho de haber sido 
absuelto el alcalde del Ayuntamiento de Carucedo por un delito de prevaricación ambiental. Como recuerda el Tribunal Supremo, "La igualdad exige un tratamiento igual por un órgano judicial o presupuestos fácticos sustancialmente iguales sin justificar el distinto tratamiento otorgado a una situación jurídica igual. En el caso, las diferencias entre ambos acusados son notorias. Mientras el acusado recurrente era el consejero delegado de una empresa respecto a la que el hecho probado refiere su inacción para no evitar el daño producido, el alcalde absuelto actúa. Según se declara probado, resolvió una solicitud de licencia que fue otorgada tras los distintos asesoramientos requeridos y que obran en el expediente, licencia que fue finalmente revocada por la jurisdicción contencioso administrativa. Como se motiva en la sentencia la exigencia típica de una actuación 'a sabiendas' del tipo penal de la prevaricación medioambiental impide la aplicación de la norma penal objeto de la acusación. El presupuesto fáctico de uno y otro acusado es distinto por lo que no existe vulneración del derecho fundamental a la igualdad".

\section{Delitos relativos a la protección de la flora, la fauna y los animales domésticos}

Para finalizar, nos referiremos a las sentencias dictadas en este período que analizan los delitos relativos a la protección de la flora, fauna y animales domésticos (artículos 332 a 337bis CP). Nos ocuparemos, en primer lugar, de las relacionadas con la actividad de caza y pesca.

En este sentido, cabe destacar la SAP de Barcelona (Sección 2ª núm. 285/2016, de 15 de abril, que viene a contribuir al amplio repertorio jurisprudencial relativo a la tipicidad de la conducta consistente en la caza de aves mediante la técnica conocida como "liga". Atendiendo al relato de los hechos, se da por probado que el acusado colocó en un charco próximo al río Besós aproximadamente 150 varillas impregnadas de una sustancia pegajosa, con la intención de capturar los pájaros que al acercarse a beber se quedaran pegado con dicho producto. En el momento de ser sorprendido por agentes del Cuerpo de Agentes Rurales de la Generalitat de Catalunya, al acusado se le intervino un jilguero (carduelis carduelis) que había capturado esa misma mañana. En la resolución del caso, la Sala rechaza en primer lugar la vulneración del principio de legalidad y recuerda la doctrina constitucional en relación con las "leyes penales en blanco". Con todo, el eje de la sentencia gira en torno a la posibilidad de subsumir los hechos probados en los artículos 
335 o 336 CP. En este sentido, la resolución admite que los hechos no son subsumibles en el artículo $335 \mathrm{CP}$ por cuanto la caza de jilgueros no se encuentra prohibida en todo caso en la legislación catalana, sino que cabe autorización para la misma. El régimen normativo sectorial establece que la caza del jilguero está sometida a autorización y ello no es equiparable, como bien argumenta la sentencia, a la prohibición expresa que requiere el artículo $335 \mathrm{CP}$, sin perjuicio de la sanción administrativa que la misma conlleve. Por el contrario, la conducta sí resulta incardinable en el artículo 336 CP. La Sala admite que la liga constituye un sistema "no selectivo" de caza, puesto que cualquier pájaro al acercarse a las varillas impregnadas puede quedar enganchado en ellas, operando este sistema de forma no discriminada de cualquier especie de fauna. A partir de ahí, la Sala argumenta que, tras la reforma penal de 2010, la eficacia del sistema no selectivo puede asimilarse en sus efectos al empleo de veneno o explosivo, por lo que la conducta resulta efectivamente punible a través del artículo $336 \mathrm{CP}$.

Otra sentencia que cabe mencionar en este ámbito es la SAP de Pamplona (Sección 2a) núm. 81/2016, de 23 de marzo, en la que se enjuicia al acusado por colocar en las ramas de varios árboles frutales cierta cantidad de cepos artesanales para pájaros, dotados de portacebos con hormigas aladas, destinados a la captura indiscriminada de aves insectívoras. La Sala excluye la aplicación al supuestos de hecho del artículo 334 CP dado que las aves insectívoras a las que se destinaban los cepos no se hallan descritas en el catálogo de especies amenazadas que fija el RD 139/2011 de 4 de diciembre. Se trata, por el contrario, de una especie silvestre con un régimen de protección especial que, conforme a la Ley de Protección de la Biodiversidad — tanto la 42/2007, en vigor en la fecha de los hechos, como la vigente Ley 33/2015 de 21 de setiembre - no puede ser objeto de caza ni de comercio aun cuando no pueda considerarse especie amenazada incardinable en el artículo $334 \mathrm{CP}$. Atendiendo a estos argumentos, la sentencia considera que los hechos sí constituyen un delito del artículo 335.1 y .4 CP, en vigor en el momento de su comisión, dado que se emplearon artes de caza expresamente prohibidas por las normas administrativas y para la caza de pájaros insectívoros que son una especie silvestre en régimen de protección especial.

La SAP de Lleida (Sección $1^{\text {a }}$ ) núm. 134/2016, de 12 de abril, analiza la concurrencia de un delito contra la flora y la fauna del artículo 335.2 CP y de un delito de tenencia ilícita de armas del artículo $563 \mathrm{CP}$. El relato de hechos probados describe la presencia del acusado en un Espacio de Interés Natural equipado con un rifle que llevaba enroscado en 
el extremo del cañón un silenciador, hallándose el arma cargada en el momento de su intervención. La sentencia recuerda que el tipo de los artículos 334 y 335 CP no sanciona la falta de autorización administrativa para la caza o la pesca, sino una conducta atentatoria contra el medio ambiente, puesto que produce efectos negativos sobre determinadas especies de flora y fauna respecto de las cuales no está prevista la posibilidad de realizar tal conducta mediante la oportuna autorización administrativa. En el supuesto de hechos, y a pesar de las alegaciones del recurrente sobre la falta de prueba, la Sala considera que la conclusión que se alcanza en la instancia resulta directamente deducible de la prueba practicada de tal modo que, si bien los agentes rurales no hallaron rebecos muertos tras la inspección de la zona, cabe afirmar que el acusado fue sorprendido mientras se dedicaba a la caza furtiva de una especie protegida como es el rebeco. Por el contrario, en relación con el delito tipificado en el artículo $563 \mathrm{CP}$ por hallarse el individuo en posesión de un arma con un silenciador, la sentencia acoge los argumentos contenidos en la STS 1962/2000, de 20 de diciembre que no consideró arma prohibida el rifle provisto de silenciador.

También las SSAP de Jaén, núm. 120/2016, de 20 de abril y núm. 175/2016, de 28 de junio, analizan supuestos de concurrencia del artículo $335.2 \mathrm{CP}$, si bien ambas centran fundamentalmente el análisis en la alegación de error en la valoración de la prueba e infracción del derecho a la presunción de inocencia. La segunda de las sentencias señaladas revoca el fallo inicialmente absolutorio al considerar que, de los datos objetivos obrantes en el atestado policial, y tras haber ratificado el acusado la declaración realizada en instancia donde reconoció ser el autor del disparo que mató a un ciervo, puede fácilmente deducirse que el animal fue abatido estando en el interior del coto y no, como pretendía el acusado, fuera de la valla del mismo. Esta observación lleva al Tribunal a estimar la apelación interpuesta por la acusación particular y condenar, en consecuencia, al acusado

Durante el período de estudio que comprende esta crónica se han dictado también algunas resoluciones que analizan la concurrencia del artículo 337 y 337bis CP. La SAP de Asturias (Sección 2a) núm. 145/2016, de 15 de marzo, mantiene la condena impuesta al recurrente por un delito de maltrato doméstico por la situación de abandono en la que se hallaron los terneros de su propiedad y la muerte de uno de ellos. La Sala valora los motivos que llevaron a la Juez de lo Penal a alcanzar la convicción sobre la autoría del maltrato animal, tanto el testimonio de los agentes del Seprona que se personaron en el 
lugar y vieron el estado de los terneros, como los informes emitidos por el veterinario que constató que los animales, de corta edad, presentaban muchas carencias.

También la SAP de Cuenca (Sección $1^{\text {a }}$ ) núm. 55/2016, de 22 de marzo, condena por el delito de maltrato de animales al responsable de haber matado, junto con otras personas no identificadas, a un total de 253 cabritos utilizando una herramienta mecánica con la que les propinaron múltiples golpes. Finalmente, la SAP de Granada (Sección 2a) núm. 405/2016 de 22 de junio, mantiene la condena a una pena de 5 meses de prisión por un delito del artículo $337 \mathrm{CP}$ al autor de un disparo intencionado sobre un gato callejero, que alcanzó al animal en el abdomen, provocándole la muerte de forma inmediata y, según se establece en los hechos probados, también muy dolorosa. 